\title{
Quick estimate of extreme floods water levels
}

\author{
André Paquier ${ }^{1, a}$, Christine Poulard ${ }^{1}$ and Jean-Baptiste Faure ${ }^{1}$ \\ ${ }^{1}$ Irstea, UR HHLY, 5, rue de la Doua BP 32138, 69616 Villeurbanne Cedex, France
}

\begin{abstract}
In order to map extreme floods (return period as high as 500 or 1000 years) for which the discharges are uncertain, it appears cost effective to use a simplified method in order to obtain estimations of water levels. Generally, maps of the 100-year flood or an equivalent historical flood are available. The method presented here exploits the information of water levels contained in these maps. To ensure consistency with the map of the 100 year flood, the method calculates the additional water depths due to the difference in peak discharge between a 100 year flood and the studied extreme flood using a 1-D Manning equation. Two examples located in France permit to discuss the most suitable choice of the model parameters among which the more uncertain one is the slope. The error is as high as about $50 \%$ for the additional water depth but the error on the flooded area is about $10 \%$. The method appears a relevant tool to define extreme flooded area if associated to the assessment of a corresponding extreme discharge.
\end{abstract}

\section{Introduction}

In France, for more than twenty years, flood hazard has been reported in the PPRI (plans for prevention of flood risks) which relied on the mapping of the 100 year flood or a historical flood if higher -, which often corresponds to a slightly higher return period. The 2007 European Flood Directive, requires to identify Areas with Potential Significant Flood Risk and map on these areas three levels of floods. In France, the three return periods are [1]:

1. a flood between 10 and 30 years return period;

2. a flood between 100 and 300 years return period;

3. a flood of about 1000 years return period.

When available, existing maps may be used - hence the return period is expressed as a range, to increase the opportunity to find existing maps. Floods similar to the typical floods of return period between 10 and 100 years can be observed and thus, a hydraulic model simulating floods can be calibrated rather easily up to this level of higher historical flood; moreover, in areas where the flood risk is high, these studies have often been already carried out. Rarer floods are more difficult to estimate with hydraulic models; and indeed extreme floods map are rare in France. Thus, as an alternative to a complicated process, with anyway a lot of uncertainty, one can propose a simplified approach to estimate rare flood extent when a 100 year flood map or an equivalent one is available and can be used as a reference. The idea is to extent the existing map to extreme flood parameters by using simple hydraulic modelling, acceptable as a first appraisal of the limits of the 1000 year flood.

[2] shows that, even for very unsteady flows such as dam break waves, applying uniform flow equation can provide a suitable relation between peak discharge and peak water depth. Then, it appears that if topography of

\footnotetext{
${ }^{a}$ Corresponding author: andre.paquier@irstea.fr
}

the valley is available, a simplified method can be based on such an approximation. Trying to minimize error, the method is applied only to obtain the 1000 year flood using the information available for the 100 year flood and assuming that this latter information is accurate.

This paper is divided into three parts, the first one detailing the principles of the method and the two following ones presenting the application of the method to two field cases: the Gardons valley that suffered a high flood in 2002, which led to a study in which a hydraulic model was calibrated also for extreme historical events, and the Montluçon city for which an estimate of the map of extreme flood was performed by a simple method in the framework of the European Directive application.

\section{Description of the method}

The method was named "Additional Depths Method" ("méthode des surcotes" in French language) because it aims at providing the difference between the water elevation accurately calculated for a well-known flood (typically the 100-year flood), and the water elevation to be estimated for an extreme flood (typically the 1000-year flood). This approach relies on the calculation of the water elevation in a river cross section, under the first main- hypothesis of a one dimension definition of the flood flow (see principle on figure 1).

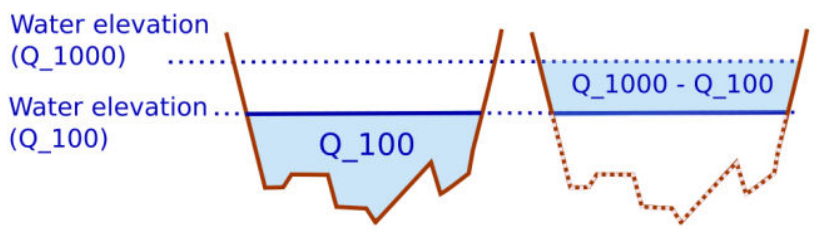

Figure 1. Sketch of the principle of the additional depths method in one cross section. 
The second hypothesis is summed up in the use of a Manning Strickler equation (1).

$$
Q=A K_{s} S^{1 / 2} R^{2 / 3}
$$

in which $Q$ is the additional flow discharge, $A$ is the additional wetted area, $S$ the slope, $K_{S}$ the Strickler coefficient and $R$ the hydraulic radius related to the additional wetted area.

Energy losses are included in a linear bottom friction, assuming that the influence of the hydraulic structures or other singularities is relatively weak. Because the land use is not homogeneous for main channel and flood plain, the Strickler coefficient is generally not constant while water level is increasing but because the additional flow is essentially in the flood plain, the Strickler coefficient to be used for calculating additional water depth can be determined from the land use of the flood plain (implying additional uncertainty that it is discussed here below). The second parameter is the slope: in case of uniform flow, the energy slope is equal to the bottom slope; in the present method, several estimates can be used for the slope: the more obvious one is the flood plain slope but this slope is difficult to estimate for one cross section because it is a parameter of a valley reach and not a local one; the water elevation slope calculated from the water elevation available for the well-known flood can be considered as an estimate of the previous slope if, for the well-known flood, the hypothesis considered for the extreme flood are already verified. The last two variables $A$ and $R$ depend on the geometry of the cross section; the accuracy of these variables can be related to the knowledge of the topography of the valley and the accuracy of the hypothesis of a 1-D flow.

\section{The case of the Gardons valley}

\subsection{Description of the case}

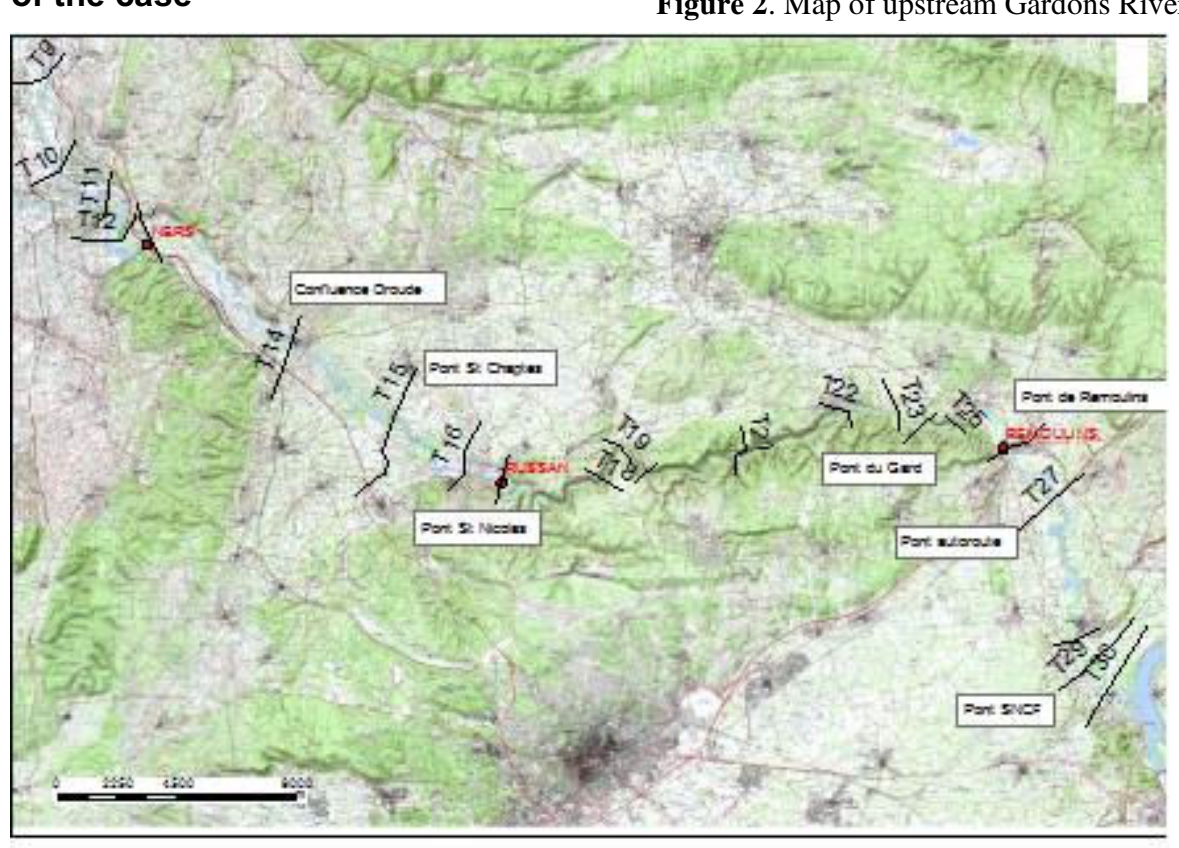

Figure 3. Map of downstream Gardons River (Gardons Réunis). 
The ANR funded Extraflo project [4] provided, an analysis of the flow for the 2002 flood and the previous high floods of the $20^{\text {th }}$ century. Thirty homogeneous geomorphological reaches were distinguished and a 1-D hydraulic model (based on RubarBE code that solves de Saint Venant equations [5]) was built. For the 600 cross sections of this latter model (space step of 200 metres), the elevations of the 100 year and 1000 year flood were calculated. The results of the RubarBE model will be considered as the reference for comparison with the various versions of the additional depths method tested here below in order to minimize the effect due to the approximation of the 1-D flow hypothesis.

In order to simplify, the additional depths method was applied using a uniform Strickler coefficient of 15 $\mathrm{m}^{1 / 3} \cdot \mathrm{s}^{-1}$ for the additional flooded area. This latter value is generally the same one as the one used for the flood plain in the RubarBE model, which means that again, the differences between the two models results are not due to the differences in the values used for this parameter; however, because the models are different, the meanings of this parameter is not exactly the same: it can be stated that, in the simplified method, the Strickler coefficient accounts for all the head losses including the influence of singularities and thus should be slightly lower than for de Saint Venant equations.

In order to be as simple as possible, the Manning Strickler equation is applied to a trapezoidal shaped section, the bottom of which is the water elevation for the 100 year flood (Figure 1) and the lateral slope corresponds to the additional width one metre higher than this latter water elevation. The method named " $h$ " includes friction both on bottom and lateral slopes while the method named "s" integrates only friction on the lateral slopes. In order to estimate the influence of simplifying the geometry, the method named "c" uses the full description of the cross section (same one as in de Saint Venant calculation) and applies average friction coefficient over the whole cross section; the average friction coefficient is calculated using the Einstein equation (power $3 / 2$ on the wetted perimeters) on the coefficient for the 100 year cross section (estimated from the 100 year water elevation) and the value $\left(15 \mathrm{~m}^{1 / 3} \cdot \mathrm{s}^{-1}\right)$ for the additional cross section.

The slope is estimated from the water elevations of the 100 year flood calculated using de Saint Venant equations. If a value below $0.01 \%$ is obtained, a value of $0.01 \%$ is applied in order to get suitable water depths [2]. Three methods are tested:

1. a slope centred on the cross section (using values obtained half space step upstream and downstream);

2. a slope centred on the cross section but calculated on three space steps;

3. the minimum of the upstream and downstream slopes.

Finally, a correction was tested in order to obtain 1000 year water elevation decreasing from upstream to downstream. The correction is required because the method is a local one and thus, this condition is not always verified. Without the correction, the method is named "sza" and with the correction "aza".

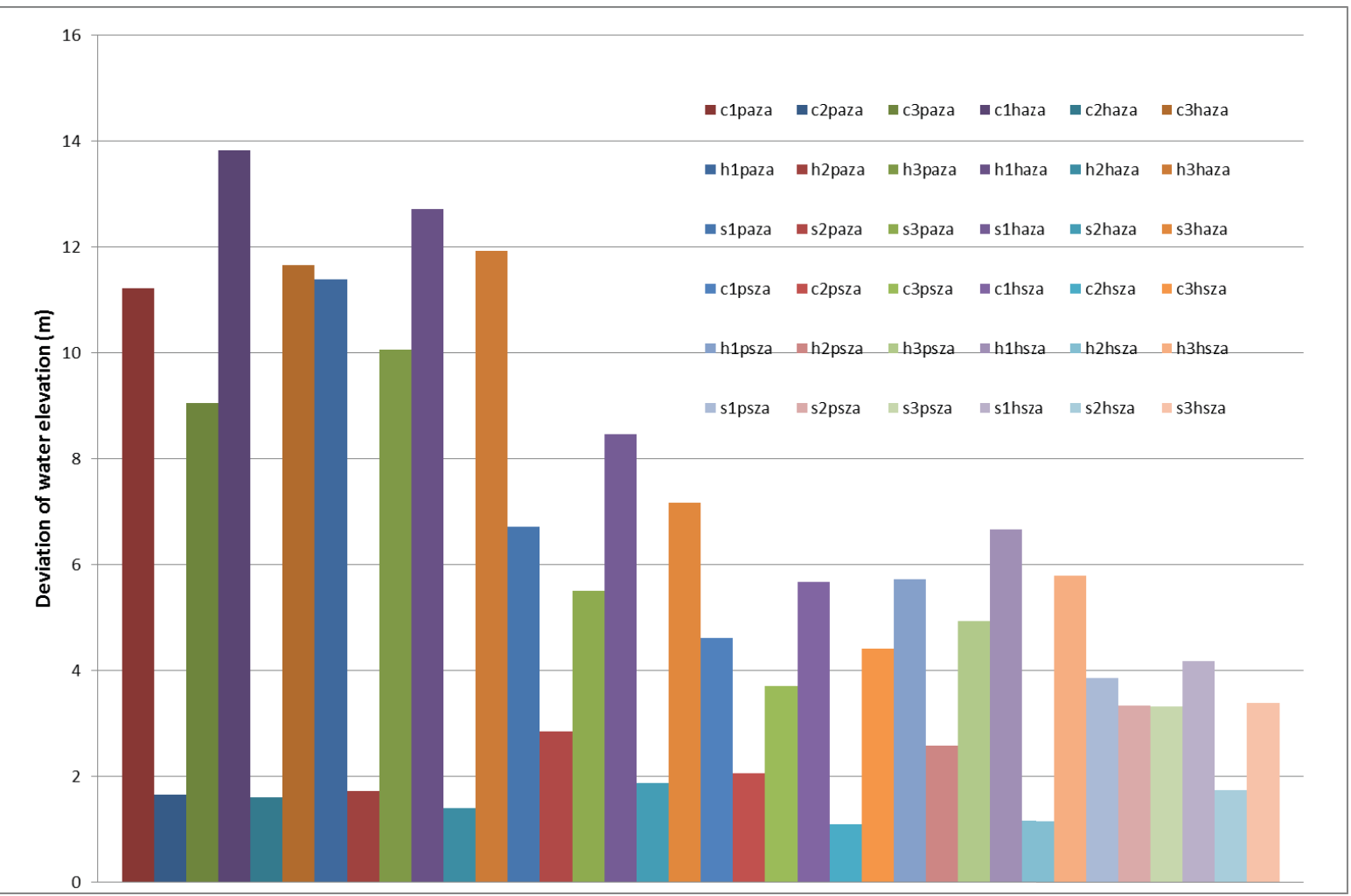

Figure 4. Standard deviation between the 1000 year elevation calculated by the reference (de Saint Venant equations with two types of calculation : «p $»$ with the same flow discharge as the simplified method, « $\mathrm{h} »$ with a discharge hydrograph reduced because of the propagation along the reach). The notation is friction (c, h or s), slope (1, 2 or 3$)$, reference (p or h), correction (sza or aza). 
On Figure 4, it appears clearly that the slope « 2 » (the averaged slope) provides the better results in nearly all the cases. The correction that prevents water elevation to increase in the stream-wise direction is not very efficient but because it simplifies the mapping, it could be used. Using reference calculation with the discharge hydrograph ("h") leads to weaker deviations because the additional depths method is generally overestimating the water elevation and thus the slight decrease of the water elevation in this reference calculation minimizes the deviation. The three methods to apply friction are relatively equivalent but method «c» (trapezoidal shape without bottom friction) provides slightly worse results.

Finally, the results (with reference to the calculation with same discharge and downstream correction «paza ») provide a deviation of $1.73 \mathrm{~m}$ for the simplified geometry ("h") and $1.64 \mathrm{~m}$ for the detailed geometry ("c"). The error on the flooded area (additional flooded areas and erroneously not flooded areas over the total flooded area) is then about $10 \%$. Deviation is slightly lower (down to $1.15 \mathrm{~m}$ ) if the comparison is carried out with the more realistic calculation using de Saint Venant equations (" $h$ " method that takes into account the flow propagation inside the reach) and is obtained without correction for decreasing water elevation, which means that this correction is not validated.

The higher deviations in water elevation are located upstream (reaches T1 and T5 on Figure 2) with moderate consequences on flooded area and in the "Gorges du Gardon" (reaches T17 and T19 on Figure 3) with nearly no consequences for flooded areas. However, the main discrepancies are in the downstream reaches (T25 to T30) in which the flood plain is very flat and thus a lower error in the water elevation means a high error on the flooded area. This latter area is also the one in which the embankments that cross the flood plain influence the flow pattern and in which the 1-D flow hypothesis can be strongly discussed.

The conclusion of this field case is the necessary use of an averaged slope to avoid the difficulties in obtaining a representative slope. Using a trapezoidal shape for the additional cross section seems convenient although it seems to create an overestimate of the water elevation. Correcting the results for providing a decreasing water elevation does not provide the best solution; it should be improved to be applied systematically.

\section{The case of Montluçon city}

In order to map the flood risk around the city of Montluçon in view of the European Flood Directive, the DDT of Allier extrapolates the results of the 100 year flood to a the 1000 year flood by a method partly similar to the additional depths method.

For this reason and because of the variability of the land use, this area was selected for a second comparison test. Similarly to the first field case, a model based on the code RubarBE was built on the 15 kilometres reach around the city. This latter model could be considered as a reference for the 1000 year flood although accurate topography is missing between the cross sections 22 to 39 of Figure 5.

The calibration of RubarBE model was limited to the upstream and downstream parts of the model in order to be close (Figure 6) to the water elevations provided by the DDT of Allier for the discharges of $250 \mathrm{~m}^{3} / \mathrm{s}$ (slightly below the 10 year peak discharge of $320 \mathrm{~m}^{3} / \mathrm{s}$ ) and 900 $\mathrm{m}^{3} / \mathrm{s}$ (the 100 year peak discharge). The Strickler coefficients after calibration vary from 30 to $50 \mathrm{~m}^{1 / 3} \cdot \mathrm{s}^{-1}$ in main channel and 8 to $15 \mathrm{~m}^{1 / 3} \cdot \mathrm{s}^{-1}$ in the flood plain. Then, the model is used for obtaining the water elevations for the 1000 year flood (peak discharge of $1430 \mathrm{~m}^{3} / \mathrm{s}$ ).

The main result for the first field case, which is the use of an averaged slope, was again tested. The correction for decreasing water elevations was not used. Only calculations for the peak discharges were used. The methods "h" (trapezoidal shape") and "c" (detailed geometry) were also tested.

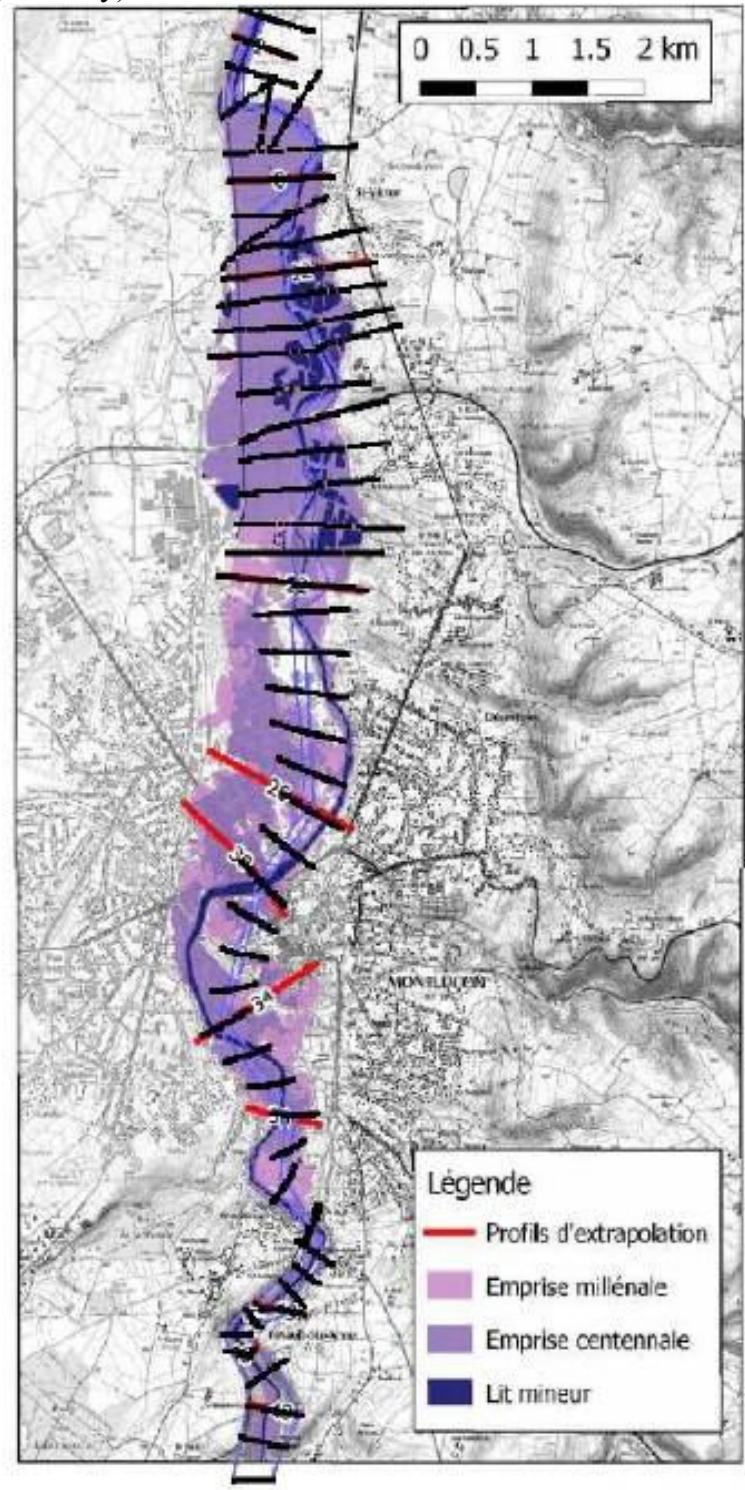

Figure 5. Map of the area (source : DDT Allier) with the cross sections used for comparison (in red), the flooded area (in blue) and the additional information of the cross sections used in RubarBE model (in black). 


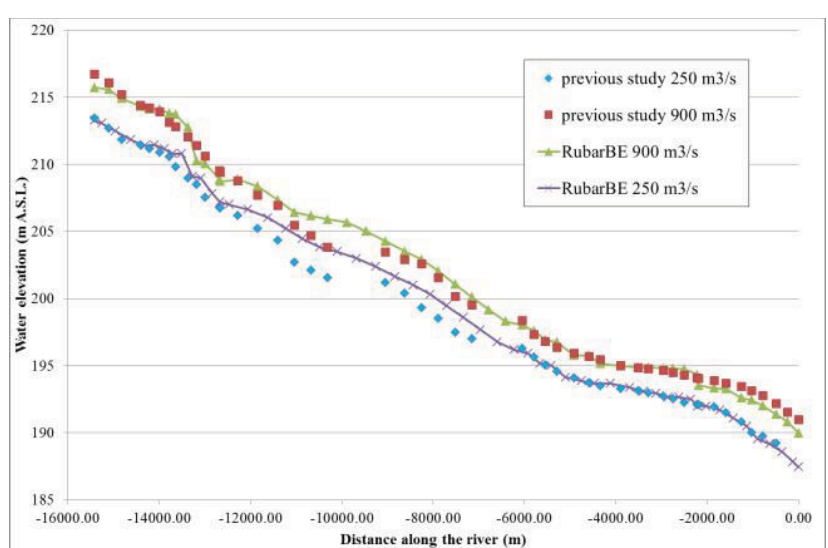

Figure 6. Comparison of water elevations along the valley for two discharges (previous study and RubarBE calculation).

The results of the additional depths method can be compared with the DDT and the RubarBE results. The second comparison used for the first field case provides an estimate of what is lost using a simplified method while the first comparison provides an estimate of what is lost using only part of the knowledge of the field data.

For the second comparison, using the same topography as in RubarBE model («c » method) provides data closer to the RubarBE results than the trapezoidal shape and then, local slope or minimum slope should be used. However, if this topography is not known (or not used for shorter data collection), the averaged slope should be used to obtain the results closer to RubarBE. Using this latter method $(« \mathrm{~h} 2$ sza $»)$, there is a slight underestimate $(0.40 \mathrm{~m}$ instead of $-0.04 \mathrm{~m}$ for «c1sza»), but the standard deviation is similar $(0.54 \mathrm{~m}$ and $0.65 \mathrm{~m})$. Here below, only this method ("h2sza") is discussed.

In tables 1 and 2, the comparison is limited to 11 cross sections considered as more representative by the DDT of Allier. The under estimate stated previously in the comparison with RubarBE calculation is also shown in table 1 for the DDT results.

\begin{tabular}{|l|l|l|l|}
\hline $\begin{array}{l}\text { Number of } \\
\text { cross } \\
\text { section }\end{array}$ & $\begin{array}{l}\text { Difference } \\
\text { DDT Allier }\end{array}$ & $\begin{array}{l}\text { Difference } \\
\text { RubarBE }\end{array}$ & $\begin{array}{l}\text { Difference } \\
\text { Additional } \\
\text { Depths } \\
\text { Method }\end{array}$ \\
\hline 2 & 0.91 & 1.30 & 0.62 \\
\hline 8 & 0.78 & 1.11 & 0.35 \\
\hline 12 & 0.8 & 0.58 & 0.18 \\
\hline 22 & 0.89 & 0.53 & 0.37 \\
\hline 26 & 0.54 & 1.09 & 0.56 \\
\hline 30 & 0.5 & 0.97 & 0.54 \\
\hline 34 & 0.53 & 1.12 & 0.69 \\
\hline 36 & 0.91 & 1.11 & 0.72 \\
\hline 43 & 1.33 & 1.08 & 0.44 \\
\hline 46 & 1.49 & 1.15 & 0.54 \\
\hline 48 & 1.1 & 1.55 & 0.89 \\
\hline
\end{tabular}

Table 1. Difference $(\mathrm{m})$ between the water elevations between the 100 year and the 1000 year floods.

Although it is not the aim and domain of the method, it was applied between the 10 year flood and the 100 year flood. Table 2 shows that similar results are obtained. Comparing the additional depths method with RubarBE, the standard deviation is $0.77 \mathrm{~m}$ (for an under estimate of
$0.18 \mathrm{~m}$ ). On the 11 representative sections (Table 2), the under estimate is even higher and particularly if compared with DDT differences.

\begin{tabular}{|l|l|l|l|}
\hline $\begin{array}{l}\text { Number } \\
\text { of cross } \\
\text { section }\end{array}$ & $\begin{array}{l}\text { Difference } \\
\text { DDT Allier }\end{array}$ & $\begin{array}{l}\text { Difference } \\
\text { RubarBE }\end{array}$ & $\begin{array}{l}\text { Difference } \\
\text { Additional } \\
\text { Depths } \\
\text { Method }\end{array}$ \\
\hline 2 & 2.46 & 2.23 & 1.88 \\
\hline 8 & 1.49 & 1.33 & 0.91 \\
\hline 12 & 1.66 & 2.12 & 1.58 \\
\hline 22 & 1.43 & 1.69 & 1.96 \\
\hline 26 & 2.58 & 1.71 & 1.81 \\
\hline 30 & 2.19 & 1.87 & 1.72 \\
\hline 34 & 2.36 & 1.21 & 1.67 \\
\hline 36 & 2.31 & 1.31 & 1.78 \\
\hline 43 & 2.61 & 2.94 & 0.95 \\
\hline 46 & 2.65 & 2.72 & 0.96 \\
\hline 48 & 2.90 & 2.40 & 1.19 \\
\hline
\end{tabular}

Table 2. Difference $(\mathrm{m})$ between the water elevations between the 10 year and the 10 à year floods.

In both comparisons with RubarBE results, it appears that the error is about $50 \%$ of the additional water depth. These results are only slightly improved if the flood plain Strickler calibrated for RubarBE model is used instead of the constant value of $15 \mathrm{~m}^{1 / 3} \cdot \mathrm{s}^{-1}$.

Going back to the first field case for which the mean additional water depth is $2.97 \mathrm{~m}$ (but with a strong variability), the error is even higher if the comparison with the peak discharge is kept as reference although the error for the flooded area is limited to about $10 \%$.

\section{Conclusion}

The two field cases shown in this paper demonstrate that the error due to the additional depths method is not linked to the approximation of the geometry of the additional flood plain nor to the Strickler value although a more accurate assessment of these parameters slightly improve the results.

The choice of the slope is the main factor that provides a slight underestimate of the results and above all generates a high variability of the results particularly in the areas in which the flow is far from a uniform flow. Although the 100 year water elevation is a quite smooth curve, the corresponding slope varies rather strongly and generates local errors. Using a valley slope, [2] shows that even for very unsteady flows, the error on the water depth can be as low as $20 \%$, which means that one can expect an improvement if a more relevant slope is used and that this slope should be smoothened to avoid local errors. However, obtaining such a slope remains a strong difficulty for which the definition of homogeneous reaches is only one step. 


\section{References}

1. http://www.bulletin-officiel.developpementdurable.gouv.fr/fiches/BO201214/met_20120014_01 00_0044.pdf.

2. Paquier A. and Robin O. (1997). CASTOR: simplified dam-break wave model. Journal of Hydraulic Engineering-ASCE, 123(8), 724-728.

3. Dezileau L., Terrier B., Berger J.F., Blanchemanche P., Latapie A ., Freydier R., Paquier A., Lang M. and Delgado J.F. (2014). Reconstitution des crues extrêmes du Gardon à partir d'une analyse paléohydrologique. Houille Blanche - Revue Internationale de l' eau, Vol. 4, pp. 44-52.

4. Lang M., Arnaud P., Carreau J., Deaux N., Dezileau L., Garavaglia F., Latapie A., Neppel L., Paquet E., Renard B., Soubeyroux J.M., Terrier B., Veysseire J.M., Aubert Y., Auffray A., Borchi F., Bernardara P., Carre J.C., Chambon D., Cipriani T., Delgado J.L., Doumenc H., Fantin R., Jourdain S., Kochanek K., Paquier A., Sauquet E., Tramblay Y. (2014). Résultats du projet ExtraFlo (ANR 2009-2013) sur l'estimation des pluies et crues extrêmes. Houille Blanche - Revue Internationale de l'eau, Vol. 2, pp. 5-13.

5. El Kadi Abderrezzak K.; Paquier A. and Gay A. (2008). One-dimensional numerical modelling of dam-break waves over movable beds: application to experimental and field cases. Environmental Fluid Mechanics, Vol. 8, pp. 169-198. 